INTERNATIONAL DESIGN CONFERENCE - DESIGN 2018

https://doi.org/10.21278/idc.2018.0189

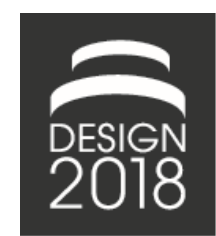

\title{
AN ONTOLOGICAL FRAMEWORK TO LINK MARKETING AND DESIGN
}

\author{
A. Casagrande-Seretti and F. Montagna
}

\begin{abstract}
Communication issues between people with different backgrounds within the product development teams are commonplace. The causes are many, including cultural differences and language barriers. Nevertheless, cooperation between Marketing and Design was proved to be strongly correlated with product success. In this paper, we study an ontological way to overcome this problem. The framework is built on the FBS ontology and refers to Consumer Behaviour theories. It was tested on a set of 77 products.
\end{abstract}

Keywords: communication, integrated product development, requirements management

\section{Introduction}

Both customer acceptance and technological superiority are key factors for innovation (Holak and Lehmann, 1990), whether they are market-pull or technology-push technologies (Di Stefano et al., 2012). Matching customer expectations and the product design remains still focal (Bailetti and Litva, 1995) and, consequently, cooperation between engineering and marketing in understanding customer needs are proved strongly correlated with the success of a new product (Cooper and Kleinschmidt, 1990). In particular, they have to communicate and cooperate during the early phases of product planning and conceptual design, and failing this integration is one of the most important causes of unsuccessful products (Gupta et al., 1985).

Actually, this integration is challenging for several reasons; but differences in departmental objectives (Brettel et al., 2011) and communication issues are the most relevant (Dougherty, 1987). Indeed, even if both departments must achieve the same company goal and share several commonalities (Ruekert and Walker Jr., 1987), such as sharing resources or trying to develop marketable products, some differences make them distant (Xie et al., 2003).

Indeed, designers speak a technical language due to an engineering culture devoted to problem-solving, while marketing people employ their own language, which is customer-oriented (Griffin and Hauser, 1992). More specifically, designers tend to conceptualise and define new products according to technical layers, while, on the other hand, marketing people turn an eye toward several psychological concepts of behaviour and motivation (Soper et al., 1995).

Moreover, methods intended to translate customer needs into appropriate technical requirements (such as quality function deployment) suffer because of several issues (van de Poel, 2007). Among them, for instance, if marketers investigate customer needs without knowing which aspects are significant for design, designers could obtain useless requirements that will not help their work.

This research aims to find a common ontological structure for enhancing the communication into interdisciplinary NPD teams, and mainly between marketing people and designers. Indeed, 
interdisciplinarity issues are widely debated in order to provide enhanced theories, frameworks, methods, and tools (Marttila and Kohtala, 2004; Brambila-Macias et al., 2016).

Starting from understanding which design variables are significant to benefit the adoption of a product, the basic idea is to create a link between methods belonging to the background of designers and methods peculiar to marketing, in order to ensure that no prospect is a priori rejected. In particular, we employed the Function-Behaviour-Structure framework introduced by Gero (1990), that is one of the most accepted design theories to support design process (Russo et al., 2013), to set the ontological variables for the classification. Moreover, this framework has been recognised as extremely useful in integrating the engineering design process and the creative process (Howard et al., 2008). Consequently, Function, Behaviour and Structure $(\mathrm{F}, \mathrm{B}, \mathrm{S})$ are considered in this paper the drivers for the design conceptualisation. With respect to them, the paper aims to link adoption choices, on one side, and marketing models, on the other side.

The first step was ontologically linking these F, B, S variables to the most known consumer behaviour theories from Marketing. These theories were divided into three categories according to their main goal: fundamental human needs models, motivation models and customer psychology models.

As a result, a matrix that relates each theory to one or more predominant F, B, S variable (for the aim of the analysis) can be derived. Similarly, for several products, we studied which technical feature appears to be the most significant for consumers. In the end, a shared conceptual framework that links consumer behaviour theories (mainly employed by marketers), F, B, S variables (used by designers) and the type of product developed by the company was obtained.

In the next section, we will discuss why integrating different functions is essential and we will review the most important consumer behaviour theories from which we developed the work. In Section 3, we will describe our goals, while the methodological approach is proposed in Section 4. Finally, conclusions and discussions are drawn in Section 5.

\section{Literature review}

The effective alignment of Design and Marketing has repeatedly been recognised as a significant business challenge (McQuarrie, 1993; Moore, 1995). Indeed, communication inside development teams is directly linked to several positive results, like superior integration (Gupta et al., 1985), enhanced understanding between functions (Souder, 1988), and greater product success (Dougherty, 1987). On the contrary, unsuccessful integration of these functions is the reason for many business failures, such as the Texas Instrument's one (Fisher et al., 1997).

Tom Allen (Allen, 1977) anticipated several of these topics and his contribution about communication flows between people involved in innovation activities was particularly insightful, demonstrating that communication diversity (i.e., discussions with people external to the team and the project) was the most significant variable for project quality.

The operative actions for integrating marketing and R\&D functions (Bailetti and Litva, 1995) has been widely investigated. As an example, Gupta and Wilemon (1990) tried to study the R\&D's perspective about actions to be applied with marketing and senior management to enhance their mutual relationships. Moreover, Souder and Chakrabarti (1978) examined how organisational factors characterising the interface between marketing and R\&D affect the cooperation of the two functions. Nevertheless, technical goals, personality, responsibilities or physical barriers still prevent achieving communication and cooperation (Griffin and Hauser, 1996). Language and cultural barriers, in particular, can arise because technical terms used by marketing differ from the ones used by designers.

From the Marketing side, many psychological concepts were investigated by scholars and had become part of marketers' background (Soper et al., 1995). In particular, behavioural psychology approaches influenced and, still, are continuing to influence consumer psychology and marketing (Wells, 2014). A first stream deeply investigated Consumer Behaviour Theory. Maslow (1943) presented the first hierarchy of fundamental needs, according to which, at any given time, people are driven in their tentative of satisfaction. Only when "lower" needs are satisfied, "higher" ones emerge. Alderfer (1969) and Max-Neef (1989) still focused on needs, developing alternatives to Maslow's theory. In the last decades, the debate of this stream of the literature has concentrated on the measure of the quality of life, 
and scientists offered several alternative approaches and methods to describing and assessing it (Diener and Suh, 1997).

Then, other studies focused on the motivation behind consumer choices. For instance, SelfDetermination Theory approaches human motivation and personality and studies people's growth tendencies and innate psychological needs (Ryan et al., 1997). Ryan and Deci (2000) identified three such needs - competence, relatedness, and autonomy - which were recognised essential for the personal well-being. Expectancy theory (Vroom, 1964) focused on motivation, which, according to the author, is a function of the multiplicative interaction between three new variables he introduced, namely valence, instrumentality, and expectancy (Oliver, 1974).

The third stream of research finally investigated customer satisfaction. In particular, Kahneman and Tversky (1979) represent a seminal contribution, demonstrating that customers perceive outcomes as gain and losses on the basis of a reference point, which usually corresponds to products currently owned. Moreover, losses have a higher impact compared to gain. Indeed, people demand much more to give up an object than they would be willing to pay to acquire it (Thaler, 1980). Samuelson and Zeckhauser (1988) provided an additional contribution explaining that people prefer products they own even if a better alternative exists. Starting from these contributions, Gourville (2006) built a behavioural framework around the three entities that drive the market potential. Finally, studying how product requirements affect customer satisfaction, Kano introduced a classification which distinguishes between five types of requirements: must-be, one-dimensional, attractive, indifferent and reverse (Matzler et al., 1996).

Therefore, by summing up, first models aim at identifying and classifying human needs, whether they be physical needs or psychological ones. Motivation models try to understand and explain the motivation behind people's choices, while customer psychology studies how consumers approach products and aim at comprehending and evaluating customer satisfaction.

From the side of Design, there exist three main streams of research as well. A first stream aimed at understanding the interactions between design and customer aspects, like Clark (1985) who proposed a framework that examined the connection between customer choices and design decisions with the objective of having an explicit representation of the forces shaping the pattern of innovation. Alternatively, instead, Meyers and Athaide (1991) explored the co-design activities, when firms and clients start cooperating in order to bridge the gap between the potential benefits of a technology and their realisation.

A second stream devoted to eliciting needs by the user. Indeed, in engineering design literature, many authors debated about marketing-oriented issues and their relationship with the success of product development projects (Cascini et al., 2013). For instance, Norman (1998) introduced the notion of human-centred design, according to which product development processes should follow an iterative pattern characterised by observations, an ideation phase, and rapid prototype and testing. Or even, Urban and von Hippel (1988) introduced an analysis of "lead users" needs as a means of improving the effectiveness of new product development. More recently, Wang and Ji (2010) tried to give companies a new method in order to better understand customer needs. In particular, they quantitatively analysed Kano's model by identifying and quantifying the relationships between customer satisfaction and the fulfilment of customer requirements.

Finally, the third stream focused on the ways to provide an operational definition of customer requirements. For instance, QFD tried to overcome language barriers and enhance communication between designers and marketers, by providing a translation mechanism from customer needs to the language of engineers (Akao, 1990).

In this paper, we want to overcome the specific debate on language again by providing a framework that is able to lever on a methodological help for both marketers and designers. In order to do so, the simplified ontology offered by the Function-Behaviour-Structure model could become a bridge between designers and marketers, and help the two to communicate with each other.

\section{Methodological approach}

In order to create a common framework that will help interdisciplinary NPD teams to cooperate, on the one hand, we relied on existing Consumer Behaviour theories used by marketers to study customer 
needs, motivation and satisfaction (Soper et al., 1995). On the other, we referred to the FunctionBehaviour-Structure ontology proposed by Gero (1990) as a means of simplifying the language of designers.

Therefore, the first step was linking the FBS framework to the most known Consumer Behaviour contributions from Marketing. In particular, we studied each theory and investigated how the variables need, motivation and satisfaction could be linked to the design variables (Function, Behaviour or Structure). Indeed, as mentioned previously, need, motivation and satisfaction reflect the main scope of the investigation of the streams of marketing research. As a result, we were able to link function, behaviour and structure to the alternative consumer behaviour theories presented above.

Similarly, we studied which are the design variables that could motivate the customer to purchase a number of products. In order to carry out both the analysis, we identified 77 products belonging to the B2C market and to the following product categories: Electronics \& Home Appliance; Clothing, Shoes \& Jewellery; Beauty \& Health; Furniture; and Sports \& Outdoors. An excerpt of the identified products is reported in Figure 1. We decided to analyse these products mainly because consumer products utility is more easily assessable, and consequently evaluating the influence of the design variables is easier.

\begin{tabular}{|c|c|c|c|c|c|}
\hline \multicolumn{2}{|c|}{ Electronics \& Home Appliances } & \multicolumn{2}{|c|}{ Clothing, Shoes \& Jewellery } & \multicolumn{2}{|c|}{ Furniture } \\
\hline Robot vacuum & 1 & Sunglasses & 24 & Mattress & 43 \\
\hline Food processor & 2 & Running shoes & 25 & Bed frame & 44 \\
\hline Steam iron & 3 & Ski suit & 26 & Closet & 45 \\
\hline Washer & 4 & $\cdots$ & & $\cdots$ & \\
\hline \multirow{6}{*}{$\begin{array}{l}\text { Toaster } \\
\text { Coffee maker } \\
\text { 22-inch TV } \\
\ldots\end{array}$} & 5 & & & & \\
\hline & 6 & \multicolumn{2}{|c|}{ Beauty \& Health } & \multicolumn{2}{|c|}{ Sports \& Outdoors } \\
\hline & 7 & Haircut & 35 & Tent & 58 \\
\hline & & Flat iron & 36 & Multitool knife & 59 \\
\hline & & Epilator & 37 & Windproof lighter & 60 \\
\hline & & & & & \\
\hline
\end{tabular}

Figure 1. Excerpt of the matrix reporting the 77 products

Firstly, we employed a qualitative and subjective approach, starting from descriptions reported by Amazon. In particular, we analysed the descriptions of the 77 products in order to categorise each product according to each of the three design variables, and understand which design variable is the driver which lead consumers to buy each product. Subsequently, in order to obtain statistically significant results, we interviewed 50 persons aged between 18 and 60, each of which chose which variable he considers significant when he/she purchases a given product. We chose interview as a method of questioning because we needed to clearly explain the meaning of F, B, S variables.

By the response rates obtained by the interviews, we applied k-means clustering (MacQueen, 1967) to group products into clusters according to their similarities and dissimilarities.

Finally, this work led to answering these following research questions: according to what a company is developing, which is the right project variable marketers should emphasise when reporting customer needs to designers? Moreover, which is the right consumer behaviour theory, they should employ in order to fulfil this task correctly?

\section{Empirical approach}

\subsection{From consumer behaviour theories to FBS variables}

Each consumer behaviour theory could be connected to one or more FBS variables, depending on how the theory interprets customer needs, motivation and satisfaction.

For instance, in Maslow's hierarchy of needs, like in all the other fundamental human needs theories, the focus is solely on physical and psychological needs. Product utility is the leading actor to fulfil physical needs, while psychological ones are usually linked to design, brand or the quality of materials. 
Therefore, these theories are linked to Function and Structure variables, since the first one refers to what the artefact is for, while the second one refers to what it looks like.

Instead, both Self-determination Theory and Expectancy Theory are connected to the Behaviour variable, since it represents the process through which outcomes are obtained, and performance is reached. Indeed, performances are strictly linked to people's need for competence in self-determination theory. Moreover, Behaviour is the only design feature able to condition the expectancy, because it affects individual performance level. In addition, product functionalities are essential to satisfy the need for autonomy proposed by the Self-determination Theory, because a higher utility cancels the effect caused by external rewards. Gourville (2006), directly, stated that new product adoption depends on the degree of behaviour change required and the degree of product change involved. These two axes are heavily influenced by Function and Behaviour because they are the two variables that established what differences had been introduced.

Finally, according to Kano model, the presence of given features satisfies the customer. These features make direct reference to product functionalities or variable related to Structure, like dimension or weight.

Links between consumer behaviour theories and FBS variables are depicted in Table 1.

Table 1. FBS variables and consumer behaviour theories

\begin{tabular}{|l|l|l|}
\hline Function & Behaviour & Structure \\
\hline Maslow's hierarchy of needs & & Maslow's hierarchy of needs \\
\hline ERG theory & & ERG theory \\
\hline Quality of life and well-being & & Quality of life and well-being \\
\hline Fundamental Human Needs & & Fundamental Human Needs \\
\hline Self-determination theory & Self-determination theory & \\
\hline & Expectancy theory & \\
\hline Kano model & & Kano model \\
\hline New product adoption & New product adoption & \\
\hline
\end{tabular}

\subsection{From products categories to FBS variables}

\subsubsection{Qualitative analysis}

Similarly, we studied the motivation behind the purchasing by customers of given products, and we linked the project variables (FBS) that could motivate customers to buy these products. In order to do so, we, firstly, employed a qualitative approach to evaluate which is the significant FBS variable by studying product descriptions reported by Amazon.

In order to carry out the analysis, we investigated 77 products belonging to the following categories Electronics \& Home Appliance; Clothing, Shoes \& Jewellery; Beauty \& Health; Furniture; and Sports $\&$ Outdoors. We used categories and product descriptions proposed by Amazon because it is the leader in online sales and it allows us to have a common basis and standardised descriptions.

In Table 2, for instance, we report the outcome of the analysis of the robot vacuum. We repeated this analysis for all the products, and we studied each of them to find which project variable lead the purchasing process. For instance, users chose a robot vacuum due to its degree of autonomy and not for its cleaning functions. Hence, Behaviour variable is the driver which lead consumers in this case.

Table 2. Robot vacuum information

\begin{tabular}{|l|l|}
\hline F & Draw - Clean \\
\hline B & $\begin{array}{l}\text { Recharge in an autonomous way - Avoid obstacles and differences in height - Battery autonomy: } 60 \\
\text { minutes }\end{array}$ \\
\hline S & No vacuum cleaner bag - Easy to empty and clean - Three different clean-up systems \\
\hline
\end{tabular}


We want to highlight the qualitative nature of this analysis that was influenced by subjective judgement. However, it was a first necessary step to define the basis for the next quantitative analysis.

\subsubsection{Cluster analysis}

In order to reach a significant quantitative result, we repeated the analysis by interviewing 50 persons aged between 18 and 60, each of which weighted the variable F, B or S in term of predominance for $\mathrm{him} /$ her when deciding to purchase a specific product.

On the basis of the obtained answers for each product (see for instance Table 3), we applied k-means clustering (MacQueen, 1967) to group products according to the variable F, B or S that was predominant. $\mathrm{K}$-means algorithm finds a partition such that the squared error between the empirical mean of a cluster and the points in the cluster is minimized (Jain, 2010).

Table 3. Excerpt the response rates matrix

\begin{tabular}{|l|l|l|l|l|}
\hline Product & ID & F & B & S \\
\hline Robot vacuum & 1 & 0.28 & 0.72 & 0 \\
\hline Food processor & 2 & 0.22 & 0.76 & 0.02 \\
\hline Steam iron & 3 & 0.78 & 0.18 & 0.04 \\
\hline$\ldots$ & $\ldots$ & $\ldots$ & $\ldots$ & $\ldots$ \\
\hline
\end{tabular}

Therefore, since we want to assign each product to one design variable, the number of clusters was set at three, namely function, behaviour and structure. Subsequently, by studying our three clusters (Figure 2), we were able to distinguish products bought for their Structure (i.e. artefacts linked to aspects related to the brand, lifestyle, or quality, like a watch, see number 28 in Figure 4) from products of which functionalities play a predominant role in the eyes of the customers (for instance, office products). Moreover, there are products adopted thanks to how they work, such as market where competition is based on technologies employed by companies, like in the home appliances industry.

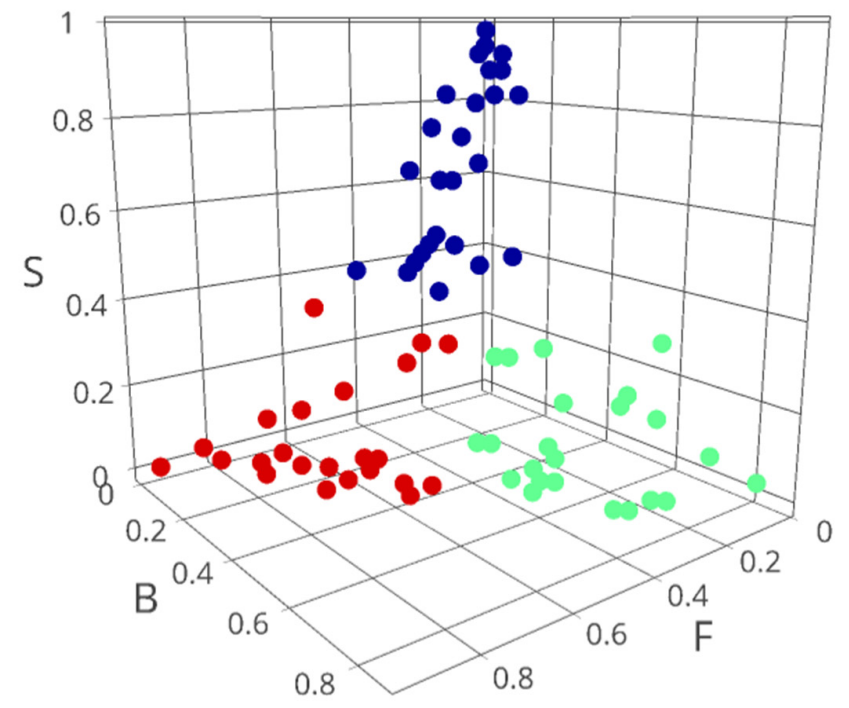

\section{CLUSTER FUNCTION}

CLUSTER BEHAVIOUR

CLUSTER STRUCTURE

Figure 2. Cluster representation

The significance of clusters was tested using ANOVA. In particular, we ran one test for each variable to evaluate if the variance was acceptable, and all the tests confirmed the robustness of the analysis. Indeed, on the basis of a 5 percent significance level, we obtained a probability of $0.000 \%$ of making a Type I error (see Figure 3). 


\begin{tabular}{|c|c|c|c|c|}
\hline & $\begin{array}{l}\text { Function } \\
\text { n }=25 \\
\text { Cluster } \# 1\end{array}$ & $\begin{array}{l}\text { Behaviour } \\
\mathrm{n}=23 \\
\text { Cluster } \# 2\end{array}$ & $\begin{array}{l}\text { Structure } \\
\mathrm{n}=29 \\
\text { Cluster \#3 }\end{array}$ & $\begin{array}{l}F=\text { value } \\
p \text { value }\end{array}$ \\
\hline $\begin{array}{l}\text { Function response rate } \\
\text { Cluster mean } \\
\text { Std. Dev. } \\
\text { Rank }\end{array}$ & $\begin{array}{l}0,65 \\
0,13 \\
1\end{array}$ & $\begin{array}{l}0,29 \\
0,11 \\
2\end{array}$ & $\begin{array}{l}0,21 \\
0,13 \\
2\end{array}$ & $\begin{array}{l}F=94,33 \\
p<0,001\end{array}$ \\
\hline $\begin{array}{l}\text { Behaviour response rate } \\
\text { Cluster mean } \\
\text { Std. Dev. } \\
\text { Rank }\end{array}$ & $\begin{array}{l}0,25 \\
0,11 \\
2\end{array}$ & $\begin{array}{l}0,60 \\
0,12 \\
1\end{array}$ & $\begin{array}{l}0,12 \\
0,08 \\
3\end{array}$ & $\begin{array}{l}F=138,74 \\
p<0,001\end{array}$ \\
\hline $\begin{array}{l}\text { Structure response rate } \\
\text { Cluster mean } \\
\text { Std. Dev. } \\
\text { Rank }\end{array}$ & $\begin{array}{l}0,01 \\
0,10 \\
3\end{array}$ & $\begin{array}{l}0,11 \\
0,10 \\
3\end{array}$ & $\begin{array}{l}0,67 \\
0,20 \\
1\end{array}$ & $\begin{array}{l}F=144,57 \\
p<0,001\end{array}$ \\
\hline
\end{tabular}

Figure 3. Results of the cluster analysis

We investigated if the cluster analysis confirmed the qualitative analysis by comparing them. The basic idea is to compare the percentage of products belonging to a given product category and linked to a given design variable, according to the two alternative analysis.

Even if some different outcomes seem to result (Figure 4), a Z-test proved that these differences were not statistically significant. Consequently, the null hypothesis of no difference cannot be rejected.

\section{QUALITATIVE}

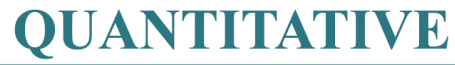

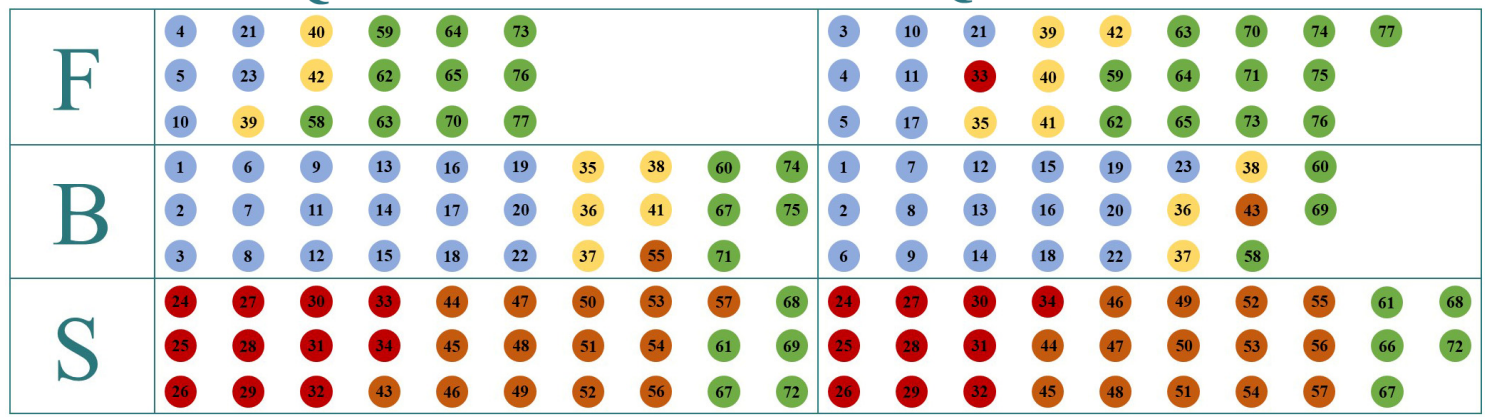

Figure 4. Comparison between qualitative and quantitative analysis results

\subsubsection{From products to product categories}

Actually, the connection between products and categories is still not univocal. Hence, we used Electre II to find a final predominance. Indeed, we aim at validating which is the most and the least relevant variable for each product category. In other words, we want to find an order of the three variables for each product category, according to predominance and significance.

Electre II belong to Multi-Criteria Decision Aid (MCDA) methods and allowed to rank several alternatives depending on some assessment criteria (Roy, 1991). We adopted Electre II approach because it is the best-known and most widely used outranking method (Hokkanen et al., 1995).

In our case, the alternatives are the five categories previously introduced, and the assessment criteria are represented by the degree of relatedness which links each product to them. Applying this method for each cluster, we were able to depict three graphs which represent how each F, B, S variable influences the purchasing of each product category (Figure 5). For instance, home furnishings convey a social message linked to the lifestyle. Hence, the Structure variable is confirmed as the driver which lead to 
purchase furniture. Similarly, sporting products are purchased because they allow the customer to perform a given activity, and hence, they are confirmed to be influenced by the Function variable.

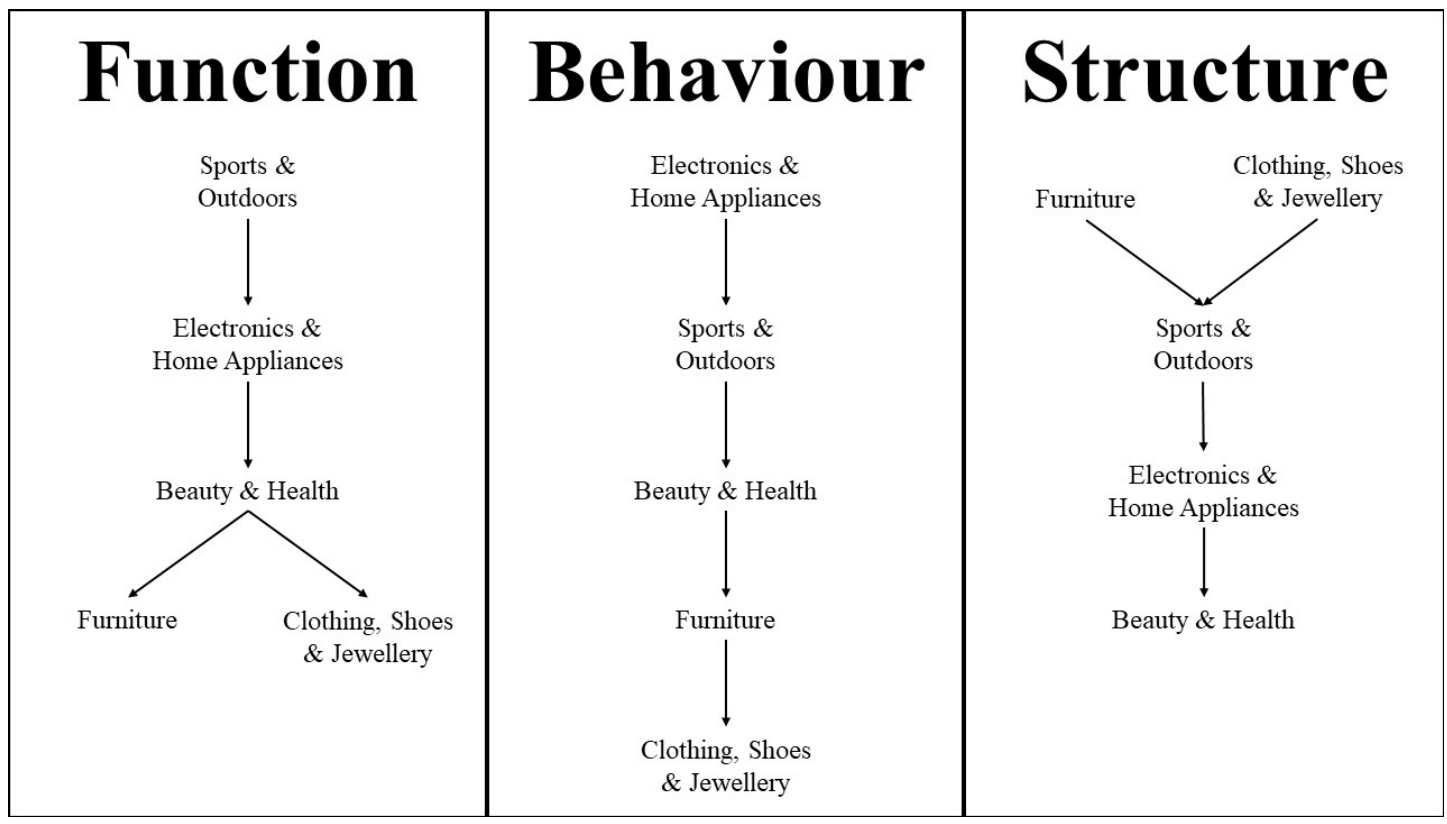

Figure 5. Ranking in the clusters

\subsection{From product categories to consumer behaviour theories}

On one side, we obtained the design variable that acts as a driver for adoption, while on the other side, we studied which models for Marketing are the most suitable when a specific design variable is interested. Now, the final step to be applied is to create the link between product categories and the most appropriate marketing model. For instance, products belonging to "Electronics \& Home Appliances " are connected to the Behaviour variable. Hence, the most suitable models to be applied in these cases are the Expectancy and Prospect Theories. Indeed, customers are driven by performance level when they have to choose "Electronics \& Home Appliances" products, and the Expectancy Theory suggests leveraging on this kind of customer effort. Moreover, these products are characterised by innovations which affect customer behaviour, and it is up to the Marketing to let customers understand how this change has a positive impact on their life.

Instead, when people buy "Beauty \& Health" products, they focus on the Function and Behaviour variables. In particular, these products allow consumers to have the autonomy and the competences to perform an activity that is challenging to perform otherwise. As an example, the blood pressure monitor let users check blood pressure at home. In Table 4, we depicted which is the appropriate Marketing model to be applied to each product category.

Table 4. Product categories and consumer behaviour theories

\begin{tabular}{|c|c|}
\hline Electronics \& Home Appliances & $\begin{array}{l}\text { Expectancy theory } \\
\text { Prospect theory }\end{array}$ \\
\hline Clothing, Shoes \& Jewellery & $\begin{array}{c}\text { Maslow's hierarchy of needs } \\
\text { Kano model }\end{array}$ \\
\hline Beauty \& Health & Self-determination theory \\
\hline Furniture & $\begin{array}{c}\text { Maslow's hierarchy of needs } \\
\text { Kano model }\end{array}$ \\
\hline Sports \& Outdoors & $\begin{array}{c}\text { Quality of life and well-being } \\
\text { Fundamental Human Needs } \\
\text { Self-determination theory }\end{array}$ \\
\hline
\end{tabular}




\section{Discussion and conclusion}

With this paper, we tried to find a link between Design and Marketing looking at customer needs and consumer behaviour through the Function-Behaviour-Structure ontology proposed by Gero (1990).

We in fact aimed at establishing a direct connection, which is based on the design variables, between different product categories and the most known consumer behaviour models. These connection helps marketing people to address customer needs towards specific design aspects, making it easier to exchange information between them and designers.

A qualitative analysis, a cluster analysis, and finally a multi-criteria method for the refinement, allowed to match the 77 identified products with F, B, S variables. Therefore, we could individuate which design variables drive consumers to acquire a given product category.

On the other side, we studied several behavioural psychology approaches influencing marketing. By analysing them, we were able to classify them according to the relevant design variables with respect to these theories.

As a consequence, during new product development, both designers and marketers can leverage on the right design variable. On one side, first ones are able to work on the more significant features according to the product category of belonging. On the other side, marketing people can use the appropriate model for precisely communicating products whose specific adoption drivers are determined.

For instance, products belonging to "Sports \& Outdoor" are designed to entertain thanks to their functionalities. Hence, Function is the reference variable. Looking for the right theories, both Quality of life and well-being and Fundamental Human Needs focus on functionalities and stress the importance of leisure activities. Therefore, marketers could set up a communication aiming at leveraging on the features allowing consumers to have fun.

Instead, style, quality and brand are key factors for a piece of furniture. Indeed, furniture express users' personality and meet social needs related to the interest in belonging to a given social group. Hence, Structure is the reference variable and marketing people, as suggested by Maslow's hierarchy of needs, should individuate the correct group and stress qualities necessary for that group.

This work provided interesting evidence; however, it needs further research efforts mainly devoted to providing higher significance through additional products and a larger number of respondents.

\section{Acknowledgement}

Thanks to Morena Recchia for her contribution to the empirical analysis.

\section{References}

Akao, Y. (1990), Quality Function Deployment: Integrating Customer Requirements into Product Design, Productivity Press, Boston.

Alderfer, C.P. (1969), "An empirical test of a new theory of human needs", Organizational Behavior and Human Performance, Vol. 4 No. 2, pp. 142-175. https://doi.org/10.1016/0030-5073(69)90004-X

Allen, T.J. (1977), Managing the Flow of Technology, MIT Press, Cambridge.

Bailetti, A.J. and Litva, P.F. (1995), "Integrating customer requirements into product designs", Journal of Product Innovation Management, Vol. 12 No. 1, pp. 3-15. https://doi.org/10.1016/0737-6782(94)00021-7

Brambila-Macias, S.A., Sakao, T. and Kowalkowski, C. (2016), "Interdissciplinary insights found for product / service system design", Proceedings of the DESIGN 2016 / 14th International Design Conference, Dubrovnik, Croatia, May 16 - 19, 2016, The Design Society, Glasgow, pp. 137-144.

Brettel, M., Heinemann, F., Engelen, A. and Neubauer, S. (2011), "Cross-functional integration of R\&D, marketing, and manufacturing in radical and incremental product innovations and its effects on project effectiveness and efficiency", Journal of Product Innovation Management, Vol. 28 No. 2, pp. 251-269. https://doi.org/10.1111/j.1540-5885.2011.00795.x

Cascini, G., Fantoni, G. and Montagna, F. (2013), "Situating needs and requirements in the FBS framework", Design Studies, Vol. 34 No. 5, pp. 636-662. https://doi.org/10.1016/j.destud.2012.12.001

Clark, K.B. (1985), "The interaction of design hierarchies and market concepts in technological evolution", Research Policy, Vol. 14 No. 5, pp. 235-251. https://doi.org/10.1016/0048-7333(85)90007-1 
Cooper, R.G. and Kleinschmidt, E.J. (1990), New Products: The Key Factors in Success, American Marketing Association, Chicago.

Di Stefano, G., Gambardella, A. and Verona, G. (2012), “Technology push and demand pull perspectives in innovation studies: Current findings and future research directions”, Research Policy, Vol. 41 No. 8, pp. 1283 1295. https://doi.org/10.1016/j.respol.2012.03.021

Diener, E. and Suh, E. (1997), "Measuring quality of life: economic, social, and subjective indicators", Social Indicators Research, Vol. 40 No. 1-2, pp. 189-216. https://doi.org/10.1023/A:1006859511756

Dougherty, D.J. (1987), New Products in Old Organizations: The Myth of The Better Mousetrap in Search of the Beaten Path, PhD thesis, Massachusetts Institute of Technology.

Fisher, R.J., Maltz, E. and Jaworski, B.J. (1997), "Enhancing communication between marketing and engineering: The moderating role of relative functional identification", Journal of Marketing, Vol. 61 No. 3, pp. 54-70. https://doi.org/ 10.2307/1251789

Gero, J.S. (1990), “Design prototypes: a knowledge representation schema for design”, AI Magazine, Vol. 11 No. 4, pp. 26-36. https://doi.org/10.1609/aimag.v11i4.854

Gourville, J. (2006), "Eager sellers and stony buyers: Understanding the psychology of new-product adoption", Harvard Business Review, Vol. 84 No. 6, pp. 98-106.

Griffin, A. and Hauser, J.R. (1992), "Patterns of communication among marketing, engineering and manufacturing - A comparison between two new product team", Management Science, Vol. 38 No. 3, pp. 360-373. https://doi.org/10.1287/mnsc.38.3.360

Griffin, A. and Hauser, J.R. (1996), "Integrating R\&D and marketing: A review and analysis of the literature", Journal of Product Innovation Management, Vol. 13 No. 3, pp. 191-215. https://doi.org/10.1016/07376782(96)00025-2

Gupta, A.K. and Wilemon, D. (1990), “Improving R\&D-marketing relations: R\&D's perspective", $R \& D$ Management, Vol. 20 No. 4, pp. 277-290. https://oi.org/10.1111/j.1467-9310.1990.tb00718.x

Gupta, A.K., Raj, S.P. and Wilemon, D. (1985), "The R\&D-marketing interface in high-technology firms", Journal of Product Innovation Management, Vol. 2 No. 1, pp. 12-24. https://doi.org/10.1016/07376782(85)90012-8

Hokkanen, J., Salminen, P., Rossi, E. and Ettala, M. (1995), "The choice of a solid waste management system using the Electre II decision-aid method", Waste Management \& Research, Vol. 13 No. 2, pp. 175-193. https://doi.org/ 10.1016/S0734-242X(95)90118-3

Holak, S.L. and Lehmann, D.R. (1990), "Purchase intentions and the dimensions of innovation: An exploratory model”, Journal of Product Innovation Management, Vol. 7 No. 1, pp. 59-73. https://doi.org/10.1016/07376782(90)90032-A

Howard, T.J., Culley, S.J. and Dekoninck, E. (2008), "Describing the creative design process by the integration of engineering design and cognitive psychology literature”, Design Studies, Vol. 29 No. 2, pp. 160-180. https://doi.org/ 10.1016/j.destud.2008.01.001

Jain, A.K. (2010), "Data clustering: 50 years beyond K-means”, Pattern Recognition Letters, Vol. 31 No. 8 , pp. 651-666. https://doi.org/10.1016/j.patrec.2009.09.011

Kahneman, D. and Tversky, A. (1979), "Prospect theory: an analysis of decision under risk", Econometrica, Vol. 47 No. 2, pp. 263-292. https://doi.org/10.2307/1914185

MacQueen, J. (1967), "Some methods for classification and analysis of multivariate observations", Proceedings of the Fifth Berkeley Symposium on Mathematical Statistics and Probability, Berkeley, California, University of California Press, Berkeley, pp. 281-297.

Marttila, T. and Kohtala, C. (2014), “Transdisciplinary platforms: Teaching sustainability to design students”, In: Srinivasan, A., Vezzoli, C., Kohtala, C., Sateesh, D., Diehl, J.C. et al. (Eds.), Product-Service System Design for Sustainability, Greenleaf Publishing Limited, UK, pp. 450-470. https://doi.org/10.9774/GLEAF.978-1909493-69-8_24

Maslow, A.H. (1943), “A theory of human motivation”, Psychological Review, Vol. 50 No. 4, pp. 370-396. https://doi.org/ 10.1037/h0054346

Matzler, K., Hinterhuber, H.H., Bailom, F. and Sauerwein, E. (1996), "How to delight your customers", Journal of Product \& Brand Management, Vol. 5 No. 2, pp. 6-18. https://doi.org/10.1108/10610429610119469 
Max-Neef, M.A., Elizalde, A. and Hopenhayn, M. (1989), "Human scale development: an option for the future", Development Dialogue, Vol. 1, pp. 7-80.

McQuarrie, E.F. (1993), Customer Visits, Sage Publications, Newbury Park.

Meyers, P.W. and Athaide, G.A. (1991), "Strategic mutual learning between producing and buying firms during product innovation”, Journal of Product Innovation Management, Vol. 8 No. 3, pp. 155-169. https://oi.org/ 10.1016/0737-6782(91)90023-R

Moore, G.A. (1995), Inside the Tornado, Harper Business, New York.

Norman, D.A. (1998), "Human-centered product development”, In: Norman, D.A. (Ed.), The Invisible Computer: Why Good Products Can Fail, the Personal Computer Is So Complex, and Information Appliances Are the Solution, MIT Press, Cambridge, Massachusetts, pp. 127-138.

Oliver, R.L. (1974), “Expectancy theory predictions of salesmen's performance”, Journal of Marketing Research, Vol. 11 No. 3, pp. 243-253. https://doi.org/10.2307/3151139

Roy, B. (1991), "The outranking approach and the foundations of electre methods", Theory and Decision, Vol. 31 No. 2, pp. 49-73. https://doi.org/10.1007/BF00134132

Ruekert, R.W. and Walker Jr., O.C. (1987), "Marketing's interaction with other functional units: A conceptual framework and empirical evidence", Journal of Marketing, Vol. 51 No. 1, pp. 1-19. https://doi.org/10.2307/1251140

Russo, D., Spreafico, C. and Duci, S. (2013), "On the co-existence of FBS and TRIZ for simplifying design process in an iterative way", Proceedings of the 19th International Conference on Engineering Design, Seoul, Korea, August 19-22, 2013, Sungkyunkwan University, Seoul, pp. 93-102.

Ryan, R.M. and Deci, E.L. (2000), "Self-determination theory and the facilitation of intrinsic motivation, social development, and well-being", American Psychologist, Vol. 55 No. 1, pp. 68-78. https://doi.org/10.1037/0003066X.55.1.68

Ryan, R.M., Kuhl, J. and Deci, E.L. (1997), "Nature and autonomy: an organizational view of social and neurobiological aspects of self-regulation in behavior and development", Development and Psychopathology, Vol. 9 No. 4, pp. 701-728. https://doi.org/10.1017/S0954579497001405

Samuelson, W. and Zeckhauser, R. (1988), "Status quo bias in decision making”, Journal of Risk and Uncertainty, Vol. 1 No. 1, pp. 7-59. https://doi.org/10.1007/BF00055564

Soper, B., Milford, G.E. and Rosenthal, G.T. (1995), "Belief when evidence does not support theory", Psychology \& Marketing, Vol. 12 No. 5, pp. 415-422. https://doi.org/10.1002/mar.4220120505

Souder, W.E. (1988), "Managing relations between R\&D and marketing in new product development projects", Journal of Product Innovation Management, Vol. 5 No. 1, pp. 6-19. https://doi.org/10.1111/1540-5885.510006

Souder, W.E. and Chakrabarti, A.K. (1978), "The R\&D-marketing interface: Results from an empirical study of innovation projects", IEEE Transactions on Engineering Management, Vol. 25 No. 4, pp. 88-93. https://doi.org/10.1109/TEM.1978.6447302

Thaler, R. (1980), "Toward a positive theory of consumer choice”, Journal of Economic Behavior \& Organization, Vol. 1 No. 1, pp. 39-60. https://doi.org/10.1016/0167-2681(80)90051-7

Urban, G.L. and von Hippel, E. (1988), "Lead user analysis for the development of new industrial products", Management Science, Vol. 34 No. 4, pp. 569-582. https://doi.org/10.1287/mnsc.34.5.569

van de Poel, I. (2007), "Methodological problems in QFD and directions for future development", Research in Engineering Design, Vol. 18 No. 1, pp. 21-36. https://doi.org/10.1007/s00163-007-0029-7

Vroom, V.H. (1964), Work and Motivation, Wiley, New York.

Wang, T. and Ji, P. (2010), "Understanding customer needs through quantitative analysis of Kano's model", International Journal of Quality \& Reliability Management, Vol. 27 No. 2, pp. 173-184. https://doi.org/10.1108/02656711011014294

Wells, V.K. (2014), "Behavioural psychology, marketing and consumer behaviour: A literature review and future research agenda", Journal of Marketing Management, Vol. 30, No. 11-12, pp. 1119-1158. https://doi.org/10.1080/0267257X.2014.929161 
Xie, J., Song. M. and Stringfellow, A. (2003), “Antecedents and Consequences of Goal Incongruity on New Product Development in Five Countries: A Marketing View", Journal of Product Innovation Management, Vol. 20 No. 3, pp. 233-250. https://doi.org/10.1111/1540-5885.2003005

Alessandro Casagrande-Seretti, PhD student

Politecnico di Torino, Department of Management and Production Engineering

Via Dante Di Nanni, 119, 10141 Torino, Italy

Email: alessandro.casagrandeseretti@polito.it 